\title{
EFFECT OF THE APPLICATION OF DIFFERENT COOKING PERIODS ON THE PHYSICOCHEMICAL PROPERTIES AND MICROBIAL SAFETY OF HOT PEPPER SAUCE
}

\author{
Ebenezer Narteh Nartey $^{1}$ | Emmanuel Tei-Mensah ${ }^{2}$ | Stephen Adusei*3 | Doreen Asante ${ }^{1}$ | Charity \\ Abaati $^{1}$
}

\footnotetext{
${ }^{1}$ Dept. of Hospitality Management, Koforidua Technical University, Koforidua, Ghana

${ }^{2}$ Dept. of Food and Postharvest Technology, Koforidua Technical University, Koforidua, Ghana

${ }^{3}$ Dept. of Laboratory Technology, University of Cape Coast, Cape Coast, Ghana
}

\section{Correspondence}

*Stephen Adusei, Department of Laboratory Technology, University of Cape Coast, Cape Coast, Ghana Email:

stephenadusei07@gmail.com

\section{Present Address}

AB 11, Abiam Street, Bibiani, Western-North Region, Ghana P. O. Box 7, Bibiani, Ghana

\begin{abstract}
Hot pepper sauce is a frequently used product in most Ghanaian homes, schools, and restaurants, which occasionally serves as condiments. The cooking period during the production process of hot pepper sauce results in physicochemical changes, which affect the quality and safety of the sauce. The study seeks to determine the effect of the application of different cooking times on the physicochemical properties and microbial safety of hot pepper sauce. The cooking periods were 10 minutes, 20 minutes, 30 minutes, and 1 hour for samples A, B, C, and D. Standard physicochemical and microbiological techniques were employed in the various analysis. Sample D (1 hour cooked) recorded the least moisture and ash content, acid insoluble ash, and a statistically significant acid value $(\mathrm{P}<0.5)$ to the other samples $(\mathrm{A}, \mathrm{B}$, and $\mathrm{C})$. The total viable count assay indicated the presence of anaerobic microorganisms in all the samples assessed, with sample D exhibiting very few microbial populations compared to the others. Staphylococcus species were detected in sample A and B only but undetected in samples C and D. Also, total coliform and Clostridium perfringens were unobserved in any of the samples. Generally, sample D had the best overall acceptability rate, with sample A having the least. This study, therefore, supports the patronization of the hour-cooked hot pepper sauce (sample D) with greater quality, longer shelf-life, and safety.
\end{abstract}

\section{KEYWORDS:}

Cooking Period, Hot Pepper Sauce, Microbial Safety, Physicochemical Properties 


\section{1 | INTRODUCTION}

Hot pepper sauce is popularly known in the local Ghanaian dialect as "shito." It is one of the desirable sauces and in many cuisine [1]. Hot pepper sauce is sometimes used as a condiment in Ghanaian dishes; containing primarily of dried fish, vegetables, oil, ginger, prawns, pepper and spices. It is classified as a condiment because it enhances and complements food ${ }^{[2]}$.

In Ghana, hot pepper sauce can be multi-faceted in the foodservice industry or domestically. It is used both in aping up a recipe during the cooking process or as a condiment to top anything from scrambled eggs to stir-fry to fresh-baked bread to finish with fiery kick ${ }^{[2]}$. Hot pepper sauce has gained popularity and is being patronized by many students and food vendors in Ghana and African countries, including Nigeria and Togo. It serves as the main food for secondary school boarding students, where it is being eaten with "gari," a popular cassava processed food. The nutritional composition of hot pepper sauce comprises of sodium, potassium, and other essential food nutrients ${ }^{[3]}$. It is known that in one tablespoon of hot pepper sauce, the body gets 190 grams of sodium and 14 grams of potassium ${ }^{[2]}$. This sauce is very good for slimming because it does not increase the number of fats in the body [3]. If one feels the need to eat healthily and lose weight, hot pepper sauce is a way forward.

The production process of hot pepper sauce comes with many risks, as the process may affect the quality and safety of the finished product. In the course of their preparations, some of these sauces, unfortunately, get burnt, mainly as a result of the various temperatures and time differences that are subjected to during the process, and this poses a serious health threat to consumers since burnt food is known to be one of the main cancerous agents in the human system 4 . On the contrary, some of these sauces may also be cooked at a relatively shorter period, adversely affecting certain physicochemical properties such as moisture content that influences microbial contamination. Hence, determining the optimal cooking period of hot pepper sauce is essential. It ensures the production and supply of safe products to consumers. Owing to the above-stated research gaps in the quality and safety of hot pepper sauces, the present study aims at determining the effect of the application of different cooking times on the physicochemical properties and microbial safety of hot pepper sauce. Finished products of hot pepper sauce samples cooked under different time conditions are shown in Figure 1

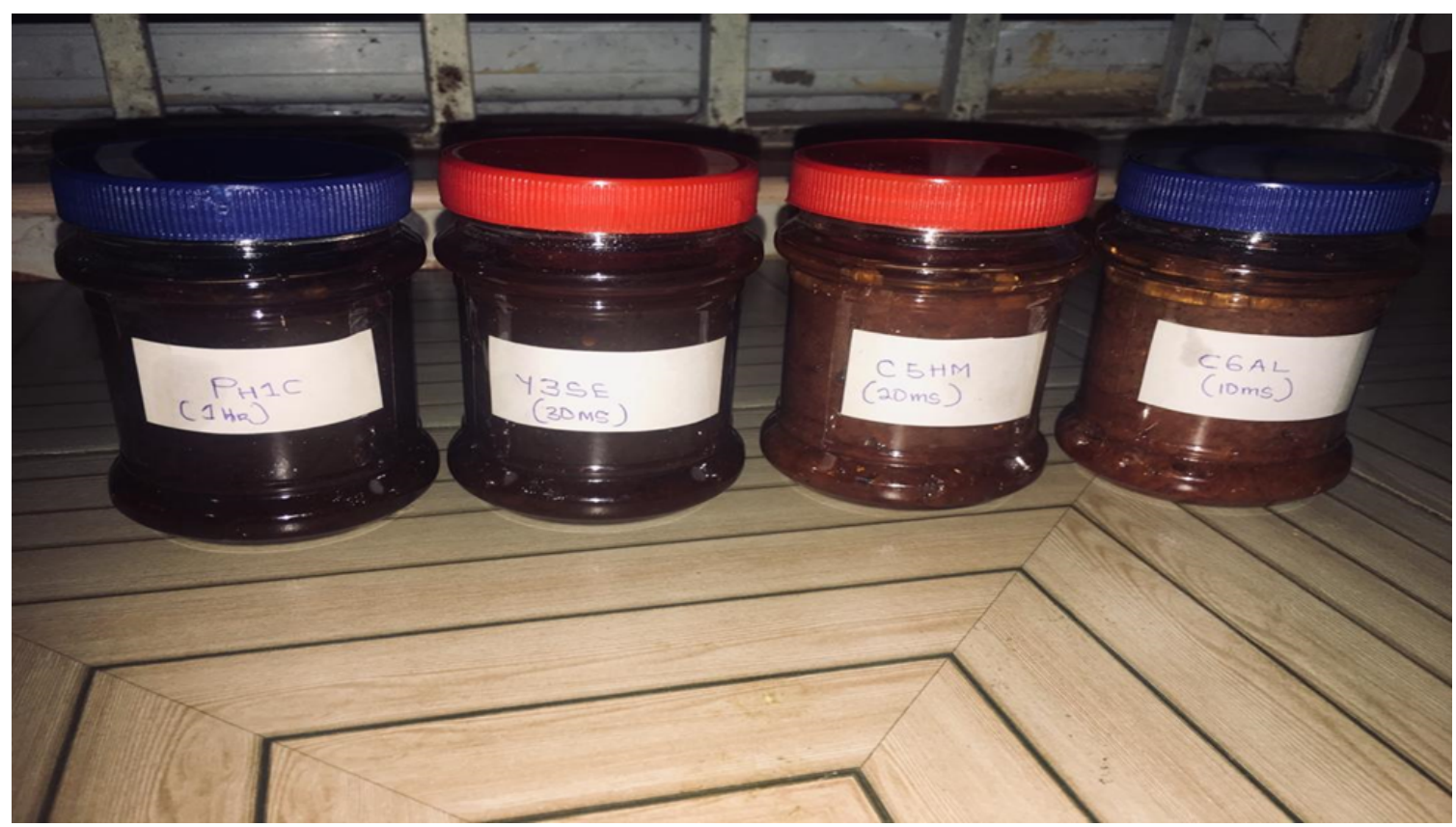

FIGURE 1 Finished products of hot pepper sauce cooked under different time conditions, showing differences in color appearances. 
TABLE 1 Ingredients with quantities for preparation of hot pepper sauce samples.

\begin{tabular}{lrlr}
\hline Ingredients & Quantity & Ingredients & Quantity \\
\hline Cooking oil (frytol) & $250 \mathrm{~g}$ & Garlic & $100 \mathrm{~g}$ \\
Fish powder & $20 \mathrm{~g}$ & Curry & $1 \mathrm{tsp}$ \\
Shrimp powder & $300 \mathrm{~g}$ & Cloves & $1 \mathrm{tsp}$ \\
Tomato puree (Gino) & $300 \mathrm{~g}$ & Pepper & $2 \mathrm{tsp}$ \\
Onions & $300 \mathrm{~g}$ & Aniseed & $1 \mathrm{tsp}$ \\
Ginger & $100 \mathrm{~g}$ & Rosemary & $1 \mathrm{tsp}$ \\
\hline Note: tsp: tea-spoon & & &
\end{tabular}

\section{2 ～PREVIOUS RESEARCHES}

The durability or shelf-life of a product is determined by the degree of a microbial load. In determining the shelf-life of a product, an emphasis is largely placed on the product's microbiological safety. Physicochemical properties such as moisture and ash content influence the microbial load of a food product. This makes it crucial to assess the impact of heat, temperature and cooking time on hot pepper sauce's physicochemical properties and microbial safety. From previous studies on hot pepper sauce, most of the researches focused on the effect of temperature and heat on the physicochemical properties and microbial load at a constant cooking period. A related study by Asafo-Adjaye ${ }^{[3]}$ on water activity and microbial safety of hot pepper sauce shows the correlation between heat and microbial load or growth. Heat and period of cooking have an impact on the rate of microbial pathogens. Based on the above facts, this research is focused on investigating the effect that the cooking time of 10 minutes, 20 minutes, 30 minutes, and 1 hour has on the physicochemical properties and microbial safety of hot pepper sauce, with little or no data available in literature. It is expected that the findings of this study will be of enormous benefit to stakeholders such as the hot pepper sauce producers, restaurants operators, the Food and Drugs Authority (FDA), and other institutions that may have an interest in the outcome of the study. These research findings will also form a background for researchers researching a related area. Consumers will also be informed of the impact of cooking periods on the physicochemical properties and microbial safety of hot pepper sauce.

\section{3 | MATERIAL AND METHOD}

\section{1 | Collection of materials}

The various ingredients were bought from the Koforidua central market, Koforidua, Ghana. The equipments and the reagents were obtained from the Department of Food/ Postharvest Technology, Koforidua Technical University, and the Department of Food Science and Nutrition at the University of Ghana. A list of ingredients with quantities for preparing the hot pepper sauce samples is presented in Table 1

\section{2 | Preparation of Materials}

A saucepan was placed on a cooking stove, and $250 \mathrm{~g}$ of cooking oil was poured into it. The oil was allowed to heat for some time, and blended onions were added and left to simmer at $100{ }^{\circ} \mathrm{C}$. The blended garlic, ginger, and fresh pepper were added and left to simmer at a very low temperature. Tomato puree was added and left to simmer once more. The mixture was stirred intermittently, and all seasonings, including the fish and shrimp powders, were added and left to simmer until a fine brown texture was obtained. The same procedure was employed to prepare all the samples under different time conditions of 10 minutes, 20 minutes, 30 minutes, and 1 hour for samples A, B, C, and D, respectively [5]. The physicochemical properties and the microbial safety of the finished products were then determined and recorded.

\section{3 | Preparation of Media}

\subsection{1 | Plate Count Agar (Vm72974462 7023)}

Twenty-two and a half grams (22.5 g) of the agar was weighed into a sterile media bottle, and $100 \mathrm{~mL}$ of distilled water was added and heated to boil till completely dissolved. The molten media was then autoclaved at $121^{\circ} \mathrm{C}$ for 15 minutes ${ }^{6}$. 


\subsection{2 | Perfringens Agar Base (Cm0587)}

Twenty-three grams ( $23 \mathrm{~g}$ ) of the agar was weighed into a sterile media bottle, and $475 \mathrm{~mL}$ of distilled water was added and heated to boil till complete dissolution was obtained. The molten media was then autoclaved at $121{ }^{\circ} \mathrm{C}$ for 15 minutes after added $25 \mathrm{~mL}$ of cooled egg yolk ${ }^{[6]}$.

\subsection{3 | Violet Red Bile Glucose Agar (Oxoid Cm0485)}

Thirty-eight and a half grams (38.5 g) of the agar was weighed into a sterile media bottle, and $1000 \mathrm{~mL}$ of distilled water was added and heated to a boil until complete dissolution. The molten media was then autoclaved at $121{ }^{\circ} \mathrm{C}$ for 15 minutes 6 .

\subsection{4 | Baird Parker Agar (Oxoid Cm0275)}

Sixty-three grams $(63 \mathrm{~g})$ of the agar was weighed into a sterile media bottle, and $1000 \mathrm{~mL}$ of distilled water was added and heated to boil till completely dissolved. The molten media was then autoclaved at $121{ }^{\circ} \mathrm{C}$ for 15 minutes after adding $25 \mathrm{~mL}$ of cooled egg yolk 6 .

\section{4 | Physicochemical Analysis}

With standard procedures, four important physicochemical properties, including moisture content, ash content, acid insoluble ash, and an acid value, were determined on the hot pepper sauce samples.

\subsection{1 | Moisture Content}

The moisture content determination was carried out according to the method by AOAC [5] Two grams of each sample was weighed using an analytical balance (Sartorius B120S, Germany). The weight of the crucible and each sample was also determined and recorded. The crucible and its content were placed in a drying oven (Fisher Isotemp® Oven, Senior Model) at a temperature of $105 \mathrm{OC}$ for three hours. The differences in weight were determined using the appropriate formula for the moisture content calculation. The procedure was then repeated for each sample in triplicates. The moisture content was calculated and expressed as a percentage using Equation 1

$$
\text { Moisture }(\%)=\frac{W_{1}-W_{2}}{W_{1}} \times 100
$$

Where; $W_{1}=$ weight in a gram of sample and crucible before drying; $W_{2}=$ weight in a gram of sample and crucible after drying.

\subsection{2 | Total Ash on Dry Basis}

A method described by William ${ }^{[5]}$ was used to determine the total ash content of the hot pepper sauce. An amount of $2 \mathrm{~g}$ each of the samples was weighed into a tarred crucible. It was then charred at a low temperature and then incinerated in a muffle furnace (Thermo Scientific) overnight until the sample was white or grayish-white, meaning the sample was free from all carbonaceous materials. The crucible and the ash sample were then cooled in a desiccator and weighed with the aid of an analytical balance (Sartorius B120S, Germany). The ignition process in the muffle furnace, cooling, and weighing at half an hour interval was repeated until the difference between two successive weighings was less than $1 \mathrm{mg}$. The total ash content was then calculated using Equation 2 and expressed as a percentage.

$$
\operatorname{Total} \operatorname{Ash}(\%)=\frac{W_{2}-W}{W_{1}} \times 100
$$

Where $W=$ weight in a gram of empty crucible; $W_{1}=$ weight in a gram of sample taken; $W_{2}=$ weight in a gram of crucible with ash. 


\subsection{3 | Acid Insoluble Ash}

To the ash samples obtained from the total ash determination, approximately $2 \mathrm{~mL}$ of $5 \mathrm{NHCl}$ was added to each sample heated on a hot plate for 10 minutes. The samples were then allowed to cool and filtered through Whatman no. 42 filter paper. The remaining residues on each filter paper were washed with distilled water until the washings were free from acid. The residue was then transferred back to the crucible and placed in an oven (Fisher Isotemp® Oven, Senior Model) at $135{ }^{\circ} \mathrm{C}$ for about 3 hours. The samples were transferred into a muffle furnace (Thermo Scientific) and ignited for 3 hours, and the dishes were cooled in a desiccator and weighed. The ignition process in the muffle furnace, cooling, and weighing at half an hour interval was repeated until the difference between two successive weighings was less than $1 \mathrm{mg}{ }^{[5]}$. The acid-insoluble ash was then calculated using Equation 3 and expressed as a percentage.

$$
\text { Acid Insoluble Ash }(\%)=\frac{W_{2}-W}{W_{1}} \times 100
$$

Where $W=$ weight in gram of empty crucible; $W_{1}=$ weight in a gram of sample taken for analysis $W_{2}=$ weight in a gram of crucible and acid-insoluble ash.

\subsection{4 | Acid Value}

Approximately $10 \mathrm{~g}$ of each of the oil samples was weighed into a $250 \mathrm{ml}$ conical flask. About $50 \mathrm{~mL}$ of freshly prepared hot ethyl alcohol (95\%) and $1 \mathrm{~mL}$ of phenolphthalein indicator solution were added to each sample. The mixtures were heated for 15 minutes in a water bath at $75^{\circ} \mathrm{C}$ and titrated while hot against standard alkali solution (KOH). A color change from colorless to light pink, persisting for 15 seconds, was observed, indicating the titration's endpoint. The normality of the KOH and the titer value, along with the weight of the sample, were used to calculate the acid value of each sample and expressed as milligram $\mathrm{KOH}$ per gram of sample taken $[$. The relation for acid value calculation is shown in Equation 4.

$$
\text { Acid Value }(\mathrm{MgKOH} / g)=\frac{56.1 \times V \times N}{W}
$$

Where $W=$ weight in a gram of sample for analysis; $V=$ Volume in $\mathrm{mL}$ of standard potassium hydroxide used; $N=$ normality of the potassium hydroxide solution.

\section{5 | Microbiological Analysis}

The qualitative and quantitative assessment of the microbial diversity of food is critical in determining the quality and safety of foods. Four basic and essential microbiological tests comprising of a total viable count, total coliform count, Staphylococcus aureus, and Clostridium perfringens were performed on the finished hot pepper sauce products.

\subsection{1 | Determination of Total Viable Count}

The Colony Count technique was used to inoculate the microorganisms. An inoculum volume of $1 \mathrm{~mL}$ from each 1:10 dilution series was pipetted into their respective labeled Petri dishes of Plate Count Agar (Vm72974462 7023). The glass spreader (hockey stick) was sterilized using ethanol and spread over a Bunsen burner. The solution was spread evenly over the agar plate using the hockey stick while carefully rotating the Petri dishes underneath an angle of $45^{\circ}$. The Petri dishes containing the agar and an evenly distributed sample solution were incubated at $37{ }^{\circ} \mathrm{C}$ for 24 hours. The colonies of microbes that appeared were then enumerated and recorded ${ }^{[7]}$.

\subsection{2 | Determination of Total Coliform Count}

The total coliform count assay was carried out by the spread plate method on Violet Red Bile Glucose Agar (Oxoid Cm0485). Dilutions of 1:10 were prepared by diluting $10 \mathrm{~g}$ of sample into $90 \mathrm{~mL}$ of sterilized peptone water for the stock dilution. One milliliter aliquot from each dilution was inoculated into Petri dishes with an already prepared Violet Red Bile Glucose Agar (VRBGA). The inoculum was evenly spread with a sterile bent rod and allowed to dry for 15 minutes at room temperature. 
TABLE 2 The effect of cooking periods on the physicochemical properties of hot pepper sauce.

\begin{tabular}{|c|c|c|c|c|c|}
\hline \multirow{2}{*}{ Property } & \multicolumn{5}{|c|}{ Sample/Time } \\
\hline & A (10 min) & B (20 min) & $\mathrm{C}(30 \mathrm{~min})$ & D (1 hr) & P-value \\
\hline Moisture (\%) & $19.57 \pm 0.01 \mathrm{a}$ & $16.14 \pm 0.00 b$ & $12.22 \pm 0.01 \mathrm{c}$ & $2.19 \pm 0.03 \mathrm{~d}$ & 0.0225 \\
\hline Total ash (\%) & $5.91 \pm 0.00 \mathrm{a}$ & $5.01 \pm 0.04 a b$ & $4.50 \pm 0.01 b$ & $2.73 \pm 0.00 \mathrm{c}$ & 0.0537 \\
\hline Acid insoluble ash (\%) & $1.92 \pm 0.01 \mathrm{a}$ & $1.65 \pm 0.03 \mathrm{ab}$ & $1.40 \pm 0.00 b$ & $0.45 \pm 0.01 \mathrm{c}$ & 0.0521 \\
\hline Acid value $(\mathrm{MgKOH} / \mathrm{g})$ & $2.15 \pm 0.01 \mathrm{a}$ & $2.00 \pm 0.02 \mathrm{ab}$ & $1.82 \pm 0.05 b$ & $0.60 \pm 0.01 \mathrm{c}$ & 0.0568 \\
\hline
\end{tabular}

The plates were inverted and incubated at $35{ }^{\circ} \mathrm{C}$ for 24 hours. The plates were then examined after the incubation period, and colonies were counted using a colony counter ${ }^{[7]}$.

\subsection{3 | Determination of Staphylococcus aureus}

Staphylococcus species were isolated and enumerated by the spread plate method and grown on Baird Parker Agar (Oxoid Cm0275). Dilutions of 1:1 were prepared by diluting $10 \mathrm{~g}$ of sample into $90 \mathrm{~mL}$ of sterilized peptone water for stock dilution. One milliliter aliquot from each dilution was inoculated into Petri dishes with an already prepared BPA (Baird Parker Agar). The inoculum was evenly spread with a sterile bent rod and dry for 15 minutes at room temperature. The plates were inverted and incubated at $35^{\circ} \mathrm{C}$ for 24 hours. After incubation, yellow colonies were counted and recorded as Staphylococcus aureus ${ }^{[7]}$.

\subsubsection{Determination of Clostridium perfringens}

The Clostridium perfringens count was also carried out by the spread plate method on Perfringens Agar Base (Cm0587). Dilutions of $1: 10$ were prepared by diluting $10 \mathrm{~g}$ of sample into $90 \mathrm{~mL}$ of sterilized peptone water for the stock dilution. One milliliter aliquot from each dilution was inoculated into Petri dishes with an already prepared Perfringens Agar Base (PAB). The inoculum was evenly spread with a sterile bent rod and allowed to dry for 15 minutes at room temperature. The Clostridium perfringens plates were incubated in an anaerobic jar at $37{ }^{\circ} \mathrm{C}$ for 24 hours. The plates were examined, and colonies were counted with a colony counter following the incubation period ${ }^{[7]}$.

\section{6 | Data Analysis}

All experiments were performed in triplicates, and the outcomes were expressed as mean \pm standard deviation. The obtained data were subjected to statistical analysis using GraphPad Prism 5.01. A One-way ANOVA was used to compare mean values among the various treatments. Using Tukey's Multiple Comparison Test, $\mathrm{P}$-values less than $0.05(\mathrm{P}<0.05)$ were considered statistically significant.

\section{4 | RESULTS AND DISCUSSION}

\section{1 | Physicochemical Analysis}

The physicochemical analysis of the hot pepper sauce samples cooked under different time conditions is presented in Table 2 and Figure 2 Each value is presented as mean \pm standard deviation. Means within a row with the same letter superscript are not significantly different ( $P>0.05$, Tukey's test), whereas those with different letter superscripts are significantly different $(\mathrm{P}<0.05)$. The moisture content of the hot pepper sauce samples ranged between $2.19 \%$ to $19.57 \%$. This was dependent on the duration of cooking of the samples. Sample D, cooked for 1 hour, had the lowest moisture content with a mean value of 2.19, followed by sample $\mathrm{C}$, which was prepared for 30 minutes, and then sample B with 20 minutes of cooking time. Having the shortest cooking time of 10 minutes, Sample A recorded the highest moisture content with a mean value of 19.57, hence more susceptible to microbial contamination than the other samples. The result of the moisture content of this present study connotes the economic value, stability, and quality of hot pepper sauces prepared with different cooking times, which affects the moisture availability for microbial activities in food. 


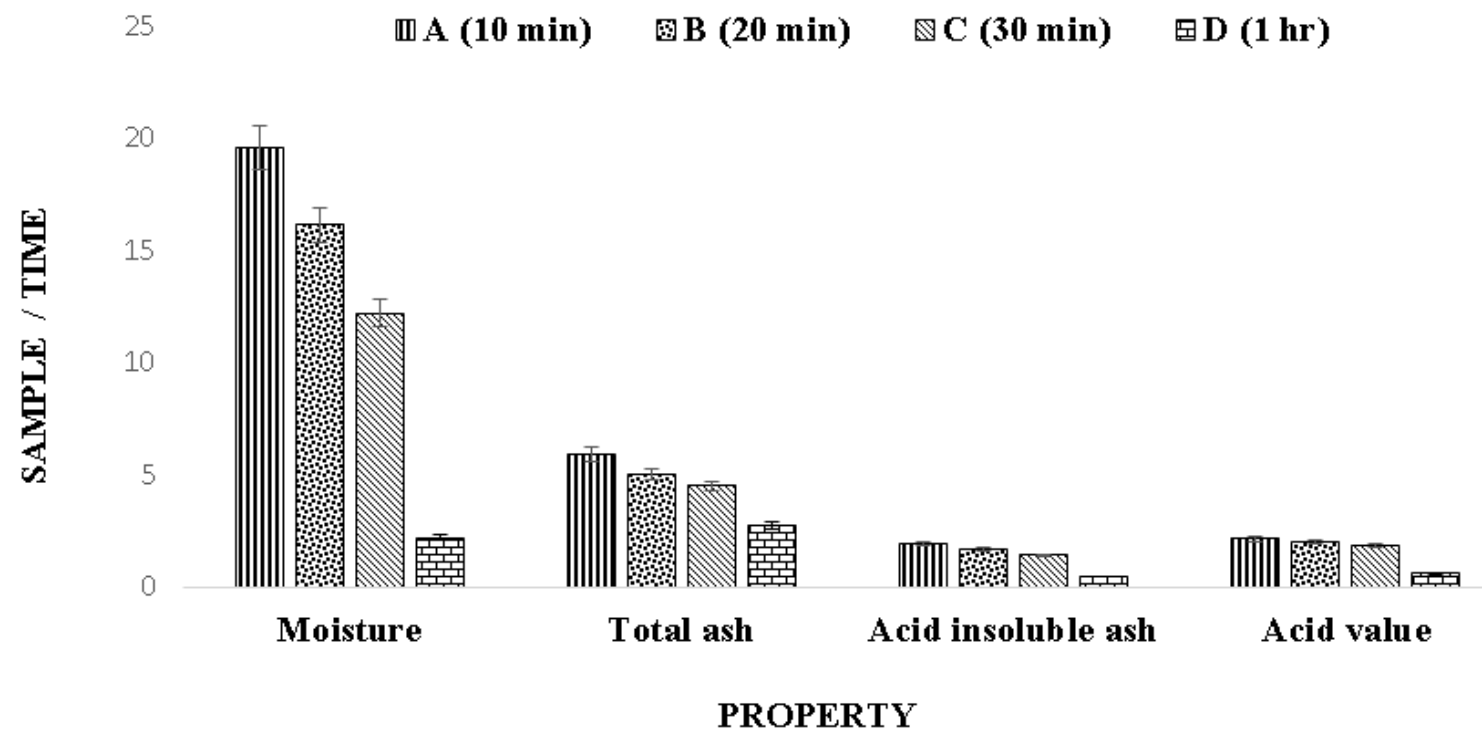

FIGURE 2 A bar chart representing the effect of cooking times on the physicochemical properties of hot pepper sauce.

The ash analysis has been predominantly used for the determination of contamination of certain foods. It represents the total mineral content in foods. The result of ash content of the hot pepper sauces represented in Table 2 did not show any significant difference $(\mathrm{P}>0.05)$ between sample A (10 min) and B $(20 \mathrm{~min})$ as well as sample B (20 min) and C (30 min). However, a significant difference $(\mathrm{P}<0.5)$ was observed between sample $\mathrm{D}(1$ hour $)$ and all the other samples. Sample A recorded the highest amount of ash $(5.91 \%)$, whereas sample D gave the least amount of $2.73 \%$. A higher ash amount suggests the presence of an inorganic adulterant, and this condition is desirable to determine the acid-insoluble ash ${ }^{8}$.

The acid-insoluble ash gives an index of mineral matter, and it is determined after digesting the total ash in $10 \% \mathrm{HCl}$. The acidinsoluble ash presented in Table 2 gave a similar pattern of result to that of the ash content, with sample A (10 min) having the highest value of $1.92 \%$ and sample D ( 1 hour) with the least amount of $0.45 \%$. High levels of acid-insoluble ash indicate the presence of sand or dirt in the sample ${ }^{9}$.

Many food processors widely use an acid value as an indicator of oil deterioration during food processing. It measures the amount of $\mathrm{KOH}$ or $\mathrm{NaOH}$ necessary to neutralize the free acids in $1 \mathrm{~g}$ of fat or oil. The statistical analysis of the acid value in Table 2 inferred no significant difference $(\mathrm{P}>0.05)$ between sample A $(10 \mathrm{~min})$ and B $(20 \mathrm{~min})$ as well as sample B $(20$ $\min )$ and $\mathrm{C}(30 \mathrm{~min})$. However, a significant difference $(\mathrm{P}<0.5)$ was perceived between sample $\mathrm{D}(1$ hour $)$ and the rest of the samples assessed. An acid value as a physicochemical property can help assess the quality of hot pepper sauce, especially its final organoleptic properties after processing $[10]$. Hence, sample D having the longest cooking time (1 hour) with the least acid value $(0.60 \mathrm{mgKOH} / \mathrm{g})$, will have a lower oil deterioration and longer shelf-life than the rest of the samples.

\section{2 | Microbiological Analysis}

\subsection{1 | Total Viable Count}

The total viable count assay indicated anaerobic microorganisms in all the samples, with some exhibiting significant microbial populations though very few. Sample D (1 hour) generally recorded low microbial growth $(1.0 \times 101 \mathrm{cfu} / \mathrm{g})$ compare to sample A $(10 \mathrm{~min})$ with the highest microbial growth of $1.10 \times 102 \mathrm{cfu} / \mathrm{g}$, and this could be accounted for by the differences in heat application periods during sample preparations. The statistical computation of the outcome did show a significant difference $(\mathrm{P}<0.05)$ in the counts obtained from the various samples at a 95\% confidence interval. The sample results did not exceed the safe and acceptable limit of $<5.0 \times 102 \mathrm{cfu} / \mathrm{g}$ established by Tortoe et al. ${ }^{[11]}$ for a total viable count of hot pepper sauces. And this establishes the relative safety of all the samples assessed. The counts recorded are presented in Table 3 and Figure 3 in colony-forming units (cfu/g). Data are mean values of triplicate determination \pm Standard deviation. Means in a row with the 
TABLE 3 The effect of cooking periods on the microbial safety of hot pepper sauce.

\begin{tabular}{|c|c|c|c|c|}
\hline \multirow{2}{*}{ Analysis } & \multicolumn{4}{|c|}{ Sample/Time } \\
\hline & A (10 min $)$ & B (20 min) & C (30 min) & D (1 hr) \\
\hline TVC (cfu/g) & $1.10 \times 102 \pm 0.02 \mathrm{a}$ & $8.00 \times 101 \pm 0.01 b$ & $5.00 \times 101 \pm 0.01 c$ & $1.00 \times 101 \pm 0.04 d$ \\
\hline $\mathrm{SA}(\mathrm{cfu} / \mathrm{g})$ & $4.00 \times 101 \pm 0.03 a$ & $2.50 \times 101 \pm 0.02 b$ & ND & ND \\
\hline $\mathrm{TCC}(\mathrm{cfu} / \mathrm{g})$ & ND & ND & ND & ND \\
\hline $\mathrm{CP}(\mathrm{cfu} / \mathrm{g})$ & ND & ND & ND & ND \\
\hline
\end{tabular}

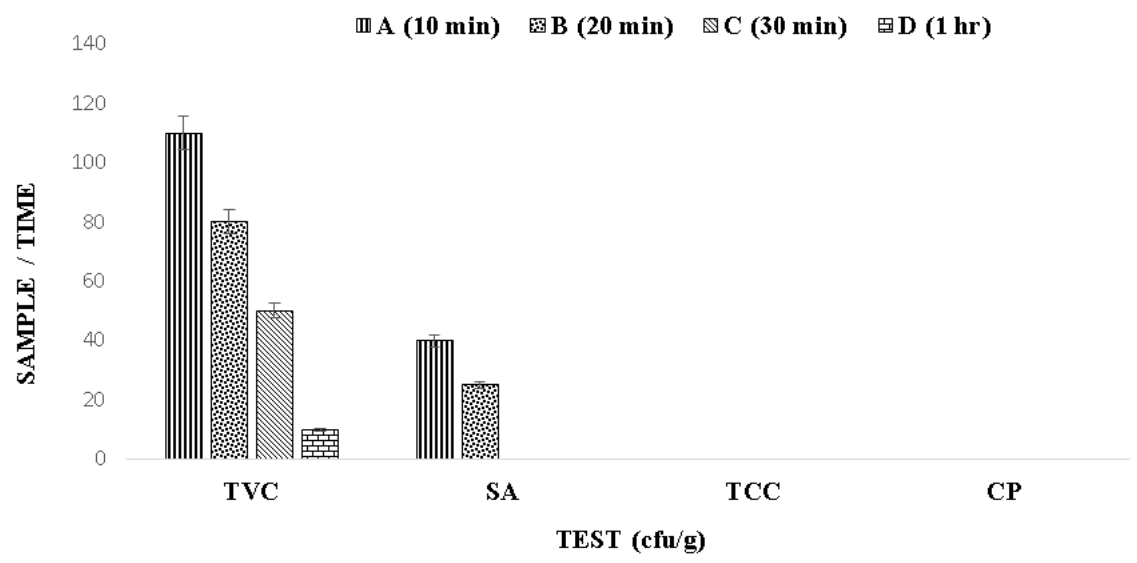

FIGURE 3 A bar chart representation of the effect of cooking times on the microbial safety of hot pepper sauce. TVC $=$ Total Viable Count, $\mathrm{SA}=$ Staphylococcus aureus, $\mathrm{TCC}=$ Total Coliform Count, $\mathrm{CP}=$ Clostridium perfringens.

same letter superscript are not significantly different $(\mathrm{P}>0.05)$ whereas those with different letter superscripts are significantly different $(\mathrm{P}<0.05$, Tukey's test.

\subsection{2 | Total Coliform Count}

The total coliform count assay result was satisfactory, with no count observed on Violet Red Bile Glucose Agar (Oxoid Cm0485) after the incubation period of 24 hours at $35^{\circ} \mathrm{C}$ as shown in Table 3 and Figure 3 The acceptable limit for hot pepper sauces, according to fda.gov [10] should be ND (Not Detected), and all the samples in this current study corroborate that limit. The absence of coliform bacteria in all the samples signifies that samples were free from fecal contamination due to the good hygienic practices employed during preparation and after production. Coliforms are a class of organisms that are of key significance in food safety as they have been associated with a couple of food poisoning and contamination circumstances recorded across the world. The pathogenic nature of coliforms causes most countries to have a sharp eye for the presence of these microorganisms in foods, with the standards ranging from 0 to $10 \mathrm{cfu} / \mathrm{g}$ as the tolerable limit. However, the coliform must be zero (0) in Ghana, as stated above 10 .

\subsection{3 | Staphylococcus Aureus}

The result of the identification of Staphylococcus aureus on the hot pepper sauce samples is displayed in Table 3 and Figure 3 The presence of Staphylococcus species in some of the samples, namely sample A (10 min) and sample B (20 min), is an indication of food contamination. The presence of Staphylococcus species in these samples signifies possible contamination during preparation or post-production, particularly through the packaging and handling processes, which encompasses direct human interfaces. However, Sample C (30 min) and D (1 hour) recorded no count of Staphylococcus species, hence free from contamination. This assertion may also result from the application of a long time of cooking to sample $\mathrm{C}$ and $\mathrm{D}$, resulting in the inhibition of microbial growth in these samples. Staphylococcus aureus is an indicator of an environmental and human-induced adulteration as the organism is commonly found to occupy living hosts such as man ${ }^{[12]}$. According to the ISO regulations, the 
detection of S. aureus in samples A and B renders them unsafe for intake. This is owing to the enormous health threats that the consumer is open to upon intake of S. aureus-infected food 12 .

\subsubsection{Clostridium Perfringens}

Clostridium perfringens is a Gram-positive, sulfite reducing anaerobic, rod-shaped, spore-forming bacteria normally present in humans and warm-blooded animals 13 . Food poisoning caused by Clostridium perfringens may occur when foods such as meats and vegetables are preserved without adequate heating and freezing before they are served. The Clostridium perfringens count assay result presented in Table 3 and Figure 3 was satisfactory with no count observed on perfringens Agar Base (Cm0587) after the incubation period of 24 hours at $37 \mathrm{OC}$ in an anaerobic jar. The absence of Clostridium perfringens bacteria in none of the samples indicates good hygienic practices employed during sample preparation and packaging following production.

\section{5 | CONCLUSION}

Food contamination can be attributed to some risk factors, including inappropriate and unhygienic cooking methods and practices. This study has revealed the effect of the application of different cooking periods on the physicochemical properties and microbial safety of hot pepper sauces prepared with the same ingredients and under similar production techniques. It can be concluded that the hot pepper sauce sample (sample D) cooked for 1 hour exhibited lower deterioration and physicochemical changes, making it safer for consumption as compared to the other samples (A, B, and C) of relatively shorter cooking periods (10, 20 and 30 minutes). Hence, 1 hour cooking period of hot pepper sauces is recommended to reduce spoilage (longer shelf-life) and inhibit microbial deterioration.

\section{CREDIT}

Conceptualization: Ebenezer Narteh Nartey; Methodology: Emmanuel Tei-Mensah; Formal analysis and investigation: Emmanuel Tei-Mensah, Doreen Asante and Charity Abaati; Writing- original draft preparation: Doreen Asante and Charity Abaati; Writing- review and editing: Stephen Adusei; Funding acquisition: No funding was received for this research; Resources: Department of Food and Postharvest Technology, Koforidua Technical University, Koforidua, Ghana; Supervision: Ebenezer Narteh Nartey.

\section{References}

1. Marras S, AgBendech M. Street food in urban Ghana: a desk-top review and analysis of findings and recommendations from existing literature. FAO Regional Office for Africa; 2016.

2. SM R. Food stability determination by macro-micro region concept in the state diagram and by defining a critical temperature. Journal of Food Engineering 2010;99:402-416.

3. Asafo-Adjaye G. Water Activity Profile and Microbial Safety of Hot Pepper Sauce "Shito". PhD thesis, Kwame Nkrumah University of Science and Technology; 2019.

4. Reynolds A, Moffatt CR, Dyda A, Hundy RL, Kaye AL, Krsteski R, et al. An outbreak of gastroenteritis due to Salmonella Typhimurium phage type 170 associated with consumption of a dessert containing raw egg. Communicable diseases intelligence 2010;34(3):329-333.

5. William H. Official Methods of Analysis: The Association of Official Analytical Chemists. 17 ed. AOAC International; 2000 .

6. Adams RM MO. Microorganisms and Food Materials: Food Microbiology. 3 ed. Royal Society of Chemistry Publishing; 2008. 
7. Fung D. Procedures and methods for one-day analysis of microbial loads in foods: Rapid Methods and Automation in Microbiology and Immunology. In: Rapid Methods and Automation in Microbiology and Immunology Springer; 1985.p. 656-664.

8. Kirk R, Sawyer R. Pearson's composition and analysis of foods. 9 ed. Longman Scientific; 2016.

9. Ghaly AE, Dave D, Budge S, Brooks M, et al. Fish spoilage mechanisms and preservation techniques. American journal of applied sciences 2010;7(7):859-877.

10. W O, A BP, Darko J, Addo A. Quality assessment of moisture content, free fatty acids and acid value of coconut oil produced in the Jomoro District of the Western Region of Ghana. Journal of Research in Agriculture 2014;3(1):205-210. http://ficuspublishers.com/Documents/AG0002.pdf.

11. Tortoe C, Johnson P, Atikpo M, Tomlins K. Systematic approach for the management and control of food safety for the street/informal food sector in Ghana. Food and Public Health 2013;3(1):59-62.

12. Liu C, Bayer A, Cosgrove SE, Daum RS, Fridkin SK, Gorwitz RJ, et al. Clinical practice guidelines by the Infectious Diseases Society of America for the treatment of methicillin-resistant Staphylococcus aureus infections in adults and children. Clinical infectious diseases 2011;52(3):285-292.

13. Rhodehamel E, Harmon S. Bacteriological Analytical Manual: Clostridium Perfringens. Food and Drug Administrtaion 2001;16:2-4.

How to cite this article: Nartey E.N., Tei-Mensah E., Adusei S., Asante D., Abaati C. (2021), Effect Of The Application Of Different Cooking Periods On The Physicochemical Properties And Microbial Safety Of Hot Pepper Sauce, IPTEK The Journal of Technology and Science, 32(1):54-63. 